\title{
Craniofacial Growth in Patients With FGFR3Pro250Arg Mutation After Fronto-Orbital Advancement in Infancy
}

\author{
Emily B. Ridgway, MD, June K. Wu, MD, Stephen R. Sullivan, MD, MPH, \\ Sivabalan Vasudavan, BDSc, MDSc, MPH, Bonnie L. Padwa, DMD, MD, \\ Gary F. Rogers, MD, JD, MPH, MBA, and John B. Mulliken, MD
}

\begin{abstract}
Background: The facial features of children with FGFR3Pro250Arg mutation (Muenke syndrome) differ from those with the other eponymous craniosynostotic disorders. We documented midfacial growth and position of the forehead after fronto-orbital advancement (FOA) in patients with the FGFR3 mutation.
\end{abstract}

Methods: We retrospectively reviewed all patients who had an FGFR3Pro250Arg mutation and craniosynostosis. Only patients who had FOA in infancy or early childhood were included. The clinical records were evaluated for type of sutural fusion; midfacial hypoplasia and other clinical data, including age at operation; type of procedures and fixation (wire vs resorbable plate); frequency of frontal readvancement, forehead augmentation, midfacial advancement; and complications.

Preoperative and postoperative sagittal orbital-globe relationship was measured by direct anthropometry. Outcome of FOA was graded according to the Whittaker classification as category I, no revision; category II, minor revisions, that is, foreheadplasty; category III, alternative bony work; category IV; redo of initial procedure (ie, secondary FOA). Midfacial position was determined by clinical examination and lateral cephalometry.

Results: A total of 21 study patients with Muenke syndrome (8 males and 13 females) were analyzed. The types of craniosynostosis were bilateral coronal $(n=15)$, of which 3 also had concurrent sagittal fusion, and unilateral coronal $(\mathrm{n}=5)$. Two patients had early endoscopic suturectomy, but later required FOA. Mean age at FOA was 22.9 months (range, 3-128 months). Secondary FOA was necessary in $40 \%$ of patients $(n=8)$, and secondary foreheadplasty in $25 \%(n=5)$ of patients. No frontal revisions were needed in the remaining $35 \%$ of patients $(n=7)$. Mean age at initial FOA was significantly younger in the group requiring repeat FOA or foreheadplasty compared with patients who did not require revision $(P<0.05)$. Location of synostosis, type of fixation, and bone grafting

From the Craniofacial Centre, Division of Plastic and Oral Surgery, Children's Hospital Boston, Harvard Medical School, Boston, Massachusetts. Received June 6, 2010.

Accepted for publication July 27, 2010.

Address correspondence and reprint requests to John B. Mulliken, MD,

Department of Plastic and Oral Surgery, Boston Children's

Hospital, 300 Longwood Ave, Boston, MA 02215;

E-mail: john.mulliken@childrens.harvard.edu

Preliminary presentation at the Xth Congress of the International

Craniofacial Society, Monterey, California, September 23, 2003.

The authors report no conflicts of interest.

Copyright (C) 2011 by Mutaz B. Habal, MD

ISSN: $1049-2275$

DOI: $10.1097 /$ SCS.0b013e3182077d93 did not significantly affect the need for revision. Only $30 \%(n=6)$ of patients developed midfacial retrusion.

Conclusions: The frequency of frontal revision in patients with Muenke syndrome who had FOA in infancy and early childhood is lower than previously reported. Age at forehead advancement inversely correlated with the incidence of relapse and need for secondary frontal procedures. Midfacial retrusion is relatively uncommon in FGFR3Pro250Arg patients.

Key Words: Muenke syndrome, fronto-orbital advancement, revisions

(J Craniofac Surg 2011;22: 455-461)

CGFR3Pro250Arg mutation-associated Muenke syndrome was First delineated as a distinct entity in 1997. ${ }^{1}$ This "new syndrome" reclassified a subset of patients with coronal synostosis who had previously been either undiagnosed, misdiagnosed, or labeled "nonsyndromic." Fusion of one or both coronal sutures occurs. Other findings in patients with this mutation include sensorineural hearing loss, midfacial retrusion, and brachydactyly. ${ }^{1-10}$ Fronto-orbital advancement (FOA) in infancy is indicated to improve forehead position, to provide orbital protection of the globe, and to reduce the likelihood of developing elevated intracranial pressure. ${ }^{11}$

Previous studies of patients with FGFR3, FGFR2, and TWIST mutations have shown that, despite FOA in infancy, there is diminished growth of the forehead, and revisions are frequently required. ${ }^{12,13}$ Midfacial retrusion is also well recognized in all these syndromes but not as well documented in Muenke syndrome. We reviewed all patients seen at our center with the molecular diagnosis of FGF3Pro250Arg. We compared the frontal and midfacial growth after surgical correction in our group to previously published studies of patients with FGFR2, FGFR3, and TWIST mutations.

\section{PATIENTS AND METHODS}

The database of the Craniofacial Centre at Children's Hospital, Boston, was culled for patients with a confirmed FGF3Pro250Arg mutation. Only patients who had undergone FOA were included. Data were compiled for date of birth, sex, family history of craniosynostosis, clinical findings, sagittal orbital-globe measurements, age at frontal advancement, method of osseous fixation, and type and age at forehead revision if needed.

Forehead position was assessed by direct anthropometry. An orbital anthropometer or metric ruler was used to determine the relationship of orbitale superioris (os) to apex corneae (acor), that is, the sagittal projection of the forehead, before and after FOA. ${ }^{14-16}$ (Fig. 1) A single examiner (J.B.M.) measured the landmarks 3 times, and the values were averaged. Measurements were recorded to the nearest $0.1 \mathrm{~mm}$ using the orbital anthropometer, and $1 \mathrm{~mm}$ with a 

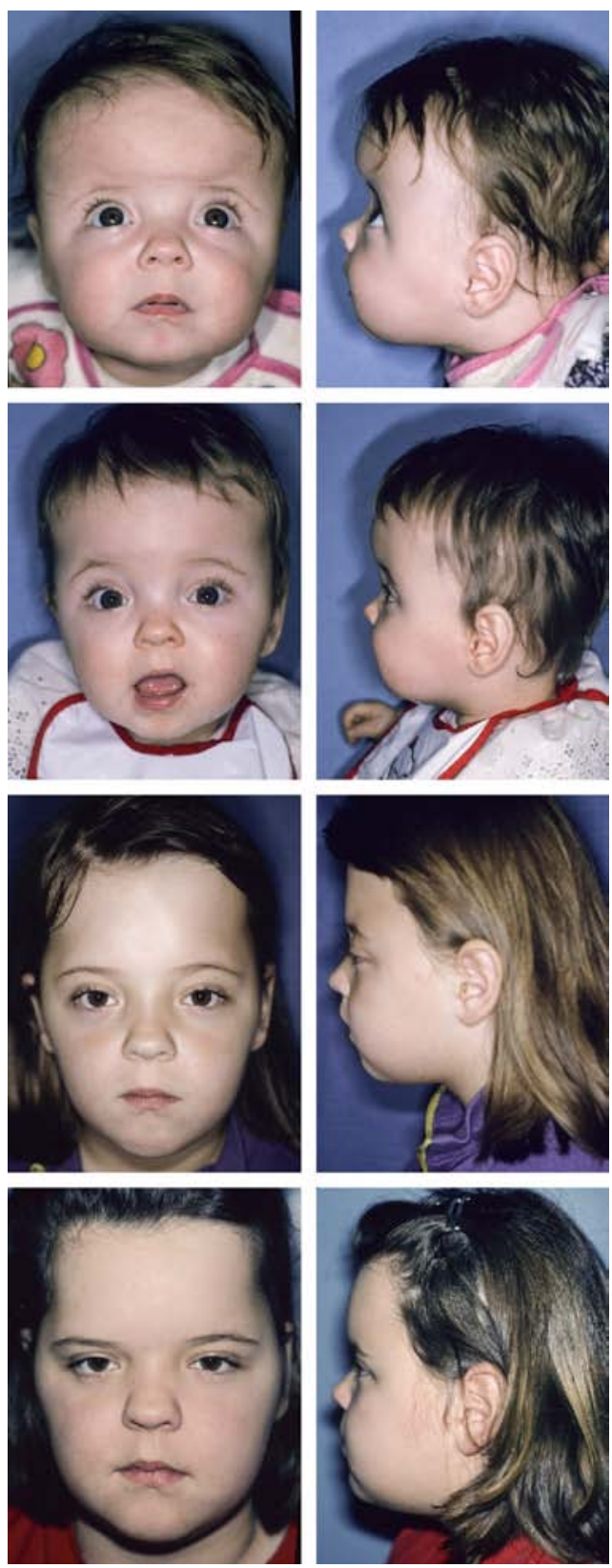

FIGURE 1. Patient with recurrent frontal retrusion 8.7 years after primary FOA at 6.1 months of age. Preoperative os-acor $-3 \mathrm{~mm}$ (above, left and right) and postoperative appearance (center above, left and right). Age 8 years before secondary FOA with os-acor $-2 \mathrm{~mm}$ (center below, left and right) and 1 year after secondary FOA (bottom, left and right).

metric ruler. ${ }^{16}$ The goal of FOA was normalization of the sagittal orbital-globe relationship (os-acor value) as previously described. ${ }^{16}$ The subsequent need for and type of revision was predicated on the os-acor relationship. Frontal readvancement was performed if os-acor was negative, and foreheadplasty was done for irregularity or asymmetry of the frontal contour in the setting of a nearly normal os-acor. Outcome was scored by the Whitaker system ${ }^{17}$ : category I: no revision; category II: foreheadplasty; category III: alternative osteotomies; and category IV: redo FOA. The revision rates were calculated and correlated with the need for revision, preoperative deformity, age at primary FOA, type of fixation, insertion of lateral bone grafts to support the advanced bandeau, and placement of particulate bone graft to fill the coronal gap.

Clinical examination and cephalometry, when available, were used to assess midfacial growth. The sagittal position of the midface was clinically assessed using the Angle molar classification. Lateral cephalograms were scanned and digitized using Dolphin Imaging Program-premium version 10.5 (Chatsworth, CA) The mean enlargement factor was recorded for each radiograph, and all linear measurements were transformed by the respective enlargement factors using the imaging software to enable direct comparison. Measurement error was assessed by repeating the digitization and measurement of the lateral cephalograms by the same examiner under the same conditions 1 month later. The coefficient of variation was calculated.

Simple descriptive statistics (mean, SD, and frequency distributions) were used to summarize data. Initial tests for normality (assessment for skewness, kurtosis, and Shapiro-Wilk) were performed to determine, where appropriate, parametric and nonparametric univariate analysis testing for the continuous variables. Statistical analysis was done using the Student's $t$-test comparing anthropometric results and outcome after FOA. The $\chi^{2}$ test and the Fisher exact test were used to compare factors associated with the likelihood of need for frontal revision. The Wilcoxon rank sum test was used to examine the difference in cephalometric values between subjects with a FGFR3Pro250Arg mutation and age- and sexmatched normative values generated by the Dolphin Imaging Program. All statistical tests were 2 -sided, and $P<0.05$ was considered to be statistically significant. Analyses were performed using SPSS for Windows version 16 (Chicago, IL).

\section{RESULTS}

\section{Patients}

Twenty-one patients in our craniofacial database had the FGFR3Pro250Arg mutation. One affected patient with unilateral lambdoidal synostosis did not require FOA and was excluded from this review. Thus, a total of 20 patients ( 13 females, 7 males) were available for analysis of craniofacial growth: 18 underwent FOA in infancy or early childhood; the other 2 were initially treated with a strip craniectomy but subsequently fused the coronal sutures and required FOA later. Thirteen patients $(65 \%)$ had a positive family history of coronal synostosis. Fifteen patients $(75 \%)$ had bilateral coronal synostosis ( 3 of which also had sagittal synostosis); 5 patients $(25 \%)$ had unilateral coronal synostosis. Supraorbital recession $(\mathrm{n}=11)$ was the most common presenting feature; 7 had turricephaly, 5 had exorbitism, and 5 had orbital hypertelorism. Other associated clinical findings are summarized in Table 1.

All patients were misdiagnosed by at least 1 health care provider at some point before formal genetic evaluation and molecular testing. Inaccurate clinical diagnoses included Pfeiffer syndrome $(n=4)$, Crouzon syndrome $(n=3)$, Pfeiffer/Crouzon $(n=1)$, familial $(n=1)$ or nonfamilial $(n=10)$ bilateral coronal synostosis, and Saethre-Chotzen syndrome $(n=1)$.

\section{Preoperative Frontal Retrusion and Revision Rate}

The severity of frontal retrusion, as assessed by the sagittal orbital-globe relationship (os-acor), was compared with the frontal revision rate. The mean preoperative os-acor was $-3.4 \mathrm{~mm}$, and the mean operative advancement of the supraorbital bar was $11.2 \mathrm{~mm}$. In unilateral cases, the os-acor of the fused side was used for analysis. In bilateral coronal synostosis, an average of the 2 sides was 
TABLE 1. Associated Findings in Patients With Muenke Syndrome

\begin{tabular}{lc}
\hline Finding & No. Patients (\%) \\
\hline Hand anomalies & $11(55)$ \\
Macrocephaly & $10(50)$ \\
Sensorineural hearing loss & $10(50)$ \\
Orbital hypertelorism & $4(20)$ \\
Chiari I malformation & $3(15)$ \\
Seizures & $3(15)$ \\
Hydrocephalus & $2(10)$ \\
Developmental delay & $2(10)$ \\
Astrocytoma & $1(5)$ \\
\hline
\end{tabular}

calculated. Whittaker classification at most recent follow-up was as follows: 7 patients $(35 \%)$, category I; $5(25 \%)$, category II (required foreheadplasty); 8 (40\%), category IV (redo FOA). The overall revision rate was $65 \%$ (Table 2 ).

Patients requiring a second FOA had a mean preoperative os-acor of $-4.3 \mathrm{~mm}$ and a mean os-acor at latest follow-up of $0.2 \mathrm{~mm}$ (Fig. 1) In contrast, patients needing only foreheadplasty had a mean preoperative os-acor of $-4.0 \mathrm{~mm}$ and a mean postoperative os-acor at latest follow-up of $+6.3 \mathrm{~mm}$ (Fig. 2). Patients who did not require revision had a mean preoperative os-acor of $-2.1 \mathrm{~mm}$ and a mean postoperative os-acor of $+5.0 \mathrm{~mm}$ (Fig. 3). Thus, patients who required a revision had a trend toward more severe preoperative recession (mean os-acor, $-4.1 \mathrm{~mm}$ ) as compared with patients not requiring revision (mean preoperative os-acor, $-2.1 \mathrm{~mm}$ ).

\section{Age at FOA and Follow-Up Assessment}

Age at initial FOA and length of follow-up were also compared with the rate of frontal revision. For patients requiring another FOA, the mean age at first FOA was 5.9 months (range, 2.510 months), and the mean length of follow-up was 12.1 (SD, 3.2) years (range, 8.6-16.6 years). For the 1 patient who was treated with strip craniectomy, the age at first FOA was later in childhood, and he was not included in this analysis. Mean age at time of secondary FOA was 8.5 years (range, 2.5-11.7 years), and mean follow-up after the secondary procedure was 6.5 years. Mean age at final evaluation was 12.6 (SD, 3.0) years (range, 9.1-16.8 years); 3 patients are being evaluated for foreheadplasty.

For patients who required foreheadplasty, the mean age at time of the initial FOA was 5.8 months (range, 3-9.5 months), and the mean length of follow-up since the first FOA was 7.8 (SD, 4.8) years (range, $2.0-15$ years). Only 1 patient has had her foreheadplasty to this date (and she required a second foreheadplasty); the remaining patients are awaiting foreheadplasty. Mean age at most recent evaluation was 8.3 (SD, 4.7) years (range, 2.3-15.3 years).

For patients who did not require revision, the mean age at FOA was 39.4 months (range, 5.9-112 months), and the mean length of follow-up was 7.7 (SD, 3.7) years (range, 2-12.5 years). For the 1 patient in this group treated with strip craniectomy, the age at first FOA was later in childhood and this patient was not included in this analysis. Mean age at final evaluation was 10.9 (SD, 3.2) years (range, 7-15.5 years) (Table 2). Overall, patients who had FOA earlier in infancy were more likely to require revisions than those having FOA in late infancy $(P<0.05)$. Patients with a longer followup had a trend toward more frequent need for revision.

\section{Unilateral Versus Bilateral Coronal Synostosis}

Subset analysis by location of synostosis showed that of the patients with unilateral coronal synostosis $(n=5), 1$ patient required repeat FOA, 1 patient required foreheadplasty, and 3 patients did not need revision. Of the patients with bilateral coronal synostosis $(n=15)$, recommendation was for repeat FOA $(n=7)$ and foreheadplasty $(n=4)$, and 4 patients did not require revision. These differences were not statistically significant. All patients with bilateral coronal synostosis and sagittal synostosis required repeat FOA (Table 3).

\section{Operative Technique}

Analysis for a possible association between operative technique and need for revisions showed that $7(77 \%)$ of 9 patients in whom the bandeau was secured with wires required revision: 5 had a second FOA, and 2 a foreheadplasty. In contrast, 4 of 7 patients whose fronto-orbital bandeau was secured with resorbable plates required revision ( 2 secondary FOA and 2 foreheadplasty). Nevertheless, the difference between these groups was not statistically significant $(P>0.05)$. The 2 older patients whose bandeau was secured with titanium plates did not require further revision.

Of the 20 patients reviewed, 13 patients had a bone graft secured behind the orbital bandeau in an effort to minimize recurrence of frontal retrusion. Eight (62\%) of 13 patients required revision ( 5 patients had repeat FOA, and 3 had foreheadplasty). Four $(80 \%)$ of 5 patients treated without bone grafting required revision (3 had repeat FOA, and 1 had foreheadplasty). Nevertheless, the difference in revision rates between the groups with and without bone graft was not significant $(P>0.05)$ (Table 3).

\section{Midfacial Retrusion}

The Angle classification was determined in 18 of 20 patients: $41 \%$ class I $(n=7), 35 \%$ class II $(n=6)$, and $24 \%$ class III $(n=5)$ (Table 3). Only 1 patient required a midfacial advancement (Fig. 4). A lateral cephalometric radiograph was available in 8 patients. Cephalometric data for patients and age- and sex-matched untreated normal subjects are presented in Table 4 . The coefficient of variation

TABLE 2. Revision Rate of Muenke Patients Treated With FOA Stratified by Age at FOA, os-acor Value, and Length of Follow-Up

\begin{tabular}{lccccc}
\hline & $\begin{array}{c}\text { Age at FOA, } \\
\text { mo }\end{array}$ & $\begin{array}{c}\text { Mean Preoperative } \\
\text { os-acor, mm }\end{array}$ & $\begin{array}{c}\text { Mean Frontal } \\
\text { Advancement, mm }\end{array}$ & $\begin{array}{c}\text { Mean Length } \\
\text { of Follow-Up, y }\end{array}$ & $\begin{array}{c}\text { Mean Age at Most } \\
\text { Recent Follow-Up, y }\end{array}$ \\
\hline Revision (n $=13)$ & 5.9 & -4.1 & 11.9 & 10.3 & 10.8 \\
Redo FOA (n $=8)$ & 5.9 & -4.3 & 11.6 & 12.1 & 16 \\
Foreheadplasty (n $=5)$ & 5.8 & -4.0 & 12.3 & 7.8 & 8.3 \\
No revision (n = 7) & 39.4 & -2.1 & 10.9 & 7.7 & 10.9 \\
$P$ & 0.033 & 0.25 & 0.40 & 0.17 & 0.59 \\
\hline
\end{tabular}



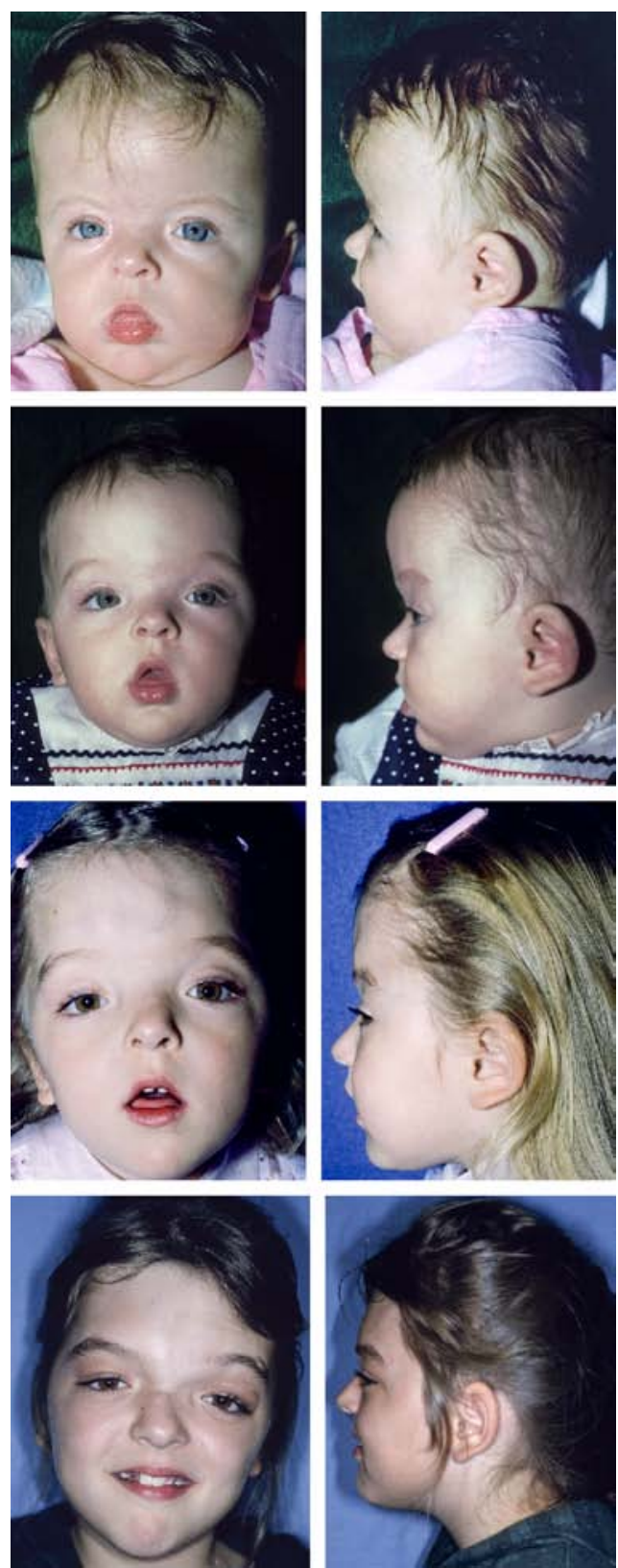

FIGURE 2. Patient with minor frontal retrusion after FOA at age 3.6 months. Preoperative (above, left and right) and postoperative views (center above, left and right). Age 5 years before revision foreheadplasty for irregular forehead contour (center below, left and right) Final appearance at 9 years of age (bottom, left and right).

was less than $5 \%$ for all the cephalometric variables on repeated measures (Table 5).

A number of statistically significant differences were observed. Patients with FGFR3Pro250Arg mutation were noted to have a reduced upper facial height, steeper palatal plane to mandibular plane angulation, increased gonial angulation, open-bite dental relationship, reduced cranial base dimension, increased angulation of the cranial base relative to the Frankfort-horizontal plane, short mandibular body (corpus) length, and reduced mid- facial length when compared with age- and sex-matched controls $(P<0.05)$.

\section{DISCUSSION}

FGFR3 is one of 4 structurally similar FGF-binding tyrosine kinase transmembrane receptors. It is known to be highly expressed in the nervous system and cartilage of developing bone and plays a major role in maturation and growth of skeletal and cranial bone. FGFR3 mutations are associated with achondroplasia, the most common form of dwarfism, thanatophoric dysplasia, crouzonodermatoskeletal syndrome (Crouzon syndrome with acanthosis nigricans), and Muenke syndrome. Clinical features of Muenke syndrome include craniosynostosis, sensoneurial hearing loss, midfacial hypoplasia, minor brachydactyly, broad but not deviated halluces, and variable cognitive delay. ${ }^{1-10}$ The phenotype is variable and this disorder has been historically confused with other types of syndromic craniosynostosis. ${ }^{18,19}$ In our series, nearly one half of our patients had been mischaracterized at one time as having another eponymous craniosynostotic syndrome. The FGFR3Pro250Arg substitution has been identified in up to $50 \%$ of patients having bilateral coronal synostosis and $7 \%$ to $10 \%$ of patients with unilateral coronal
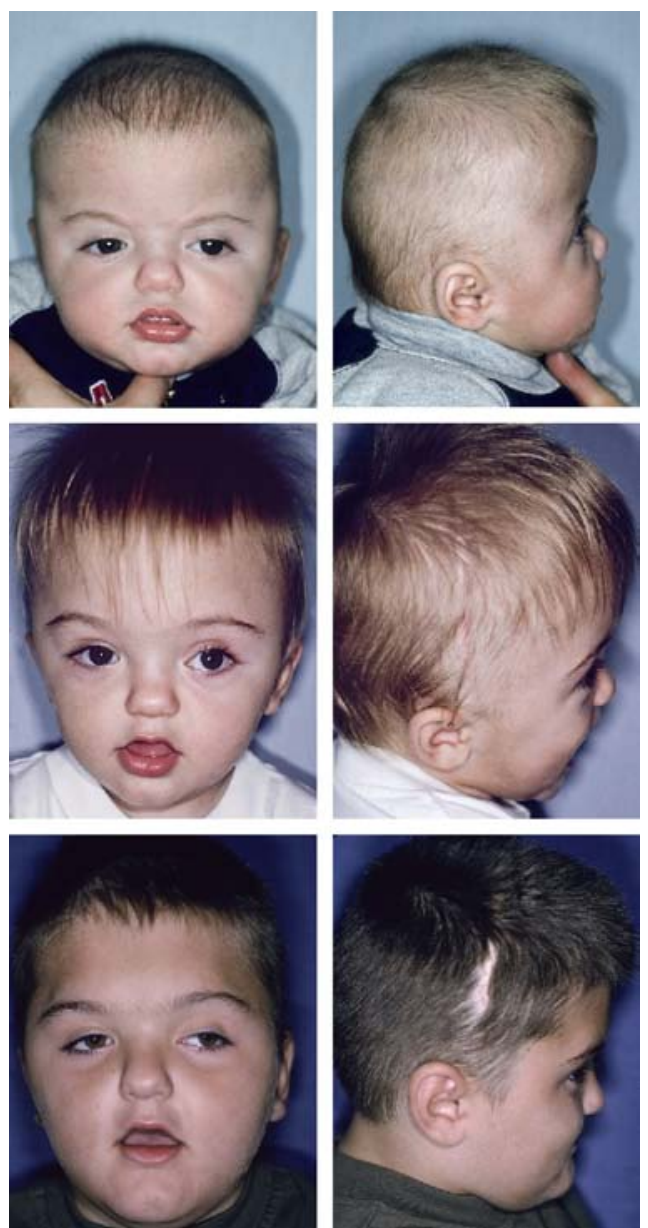

FIGURE 3. Frontal and lateral views of a male patient with FGFR3Pro250Arg with a satisfactory frontal sagittal relationship after FOA at 5.9 months of age. Preoperative os-acor $0 \mathrm{~mm}$ (above, left and right) and postoperative views (center, left and right). At age 13 years with os-acor $+7.5 \mathrm{~mm}$ (bottom, left and right). No revisions have been performed. 
TABLE 3. Revision Rate of Muenke Patients Treated With FOA Stratified by Operative Details Including Type of Fixation and Cortical and Particulate Bone Grafting of the Coronal Gap

\begin{tabular}{|c|c|c|c|c|c|}
\hline & $\begin{array}{l}\text { Revision } \\
(\mathrm{n}=12)\end{array}$ & $\begin{array}{l}\text { Redo FOA } \\
\quad(\mathbf{n}=\mathbf{8})\end{array}$ & $\begin{array}{l}\text { Foreheadplasty } \\
\qquad(\mathrm{n}=4)\end{array}$ & $\begin{array}{c}\text { No } \\
\text { Revision } \\
(n=6)\end{array}$ & $P$ \\
\hline \multicolumn{6}{|l|}{ Type of synostosis } \\
\hline $\begin{array}{l}\text { Bilateral } \\
\text { coronal } \\
\text { synostosis } \\
(\mathrm{n}=15)\end{array}$ & 11 & 7 & 4 & 4 & 0.29 \\
\hline $\begin{array}{l}\text { Unilateral } \\
\text { coronal } \\
\text { synostosis } \\
(\mathrm{n}=5)\end{array}$ & 2 & 1 & 1 & 3 & \\
\hline \multicolumn{6}{|l|}{ Fixation } \\
\hline $\begin{array}{l}\text { No fixation } \\
\quad(\mathrm{n}=1)\end{array}$ & 1 & 1 & 0 & 0 & \\
\hline $\begin{array}{l}\text { Wire only } \\
\quad(\mathrm{n}=9)\end{array}$ & 7 & 5 & 2 & 2 & 0.60 \\
\hline $\begin{array}{l}\text { Resorbable } \\
\text { plating } \\
(\mathrm{n}=7)\end{array}$ & 4 & 2 & 2 & 3 & \\
\hline $\begin{array}{l}\text { Titanium } \\
\text { plating } \\
(\mathrm{n}=2)\end{array}$ & 0 & 0 & 0 & 2 & \\
\hline \multicolumn{6}{|c|}{ Lateral coronal gap } \\
\hline $\begin{array}{l}\text { Bone graft } \\
\quad(\mathrm{n}=13)\end{array}$ & 8 & 5 & 3 & 5 & 0.62 \\
\hline $\begin{array}{l}\text { No bone graft } \\
\quad(\mathrm{n}=5)\end{array}$ & 4 & 3 & 1 & 1 & \\
\hline \multicolumn{6}{|c|}{ Superomedial coronal gap } \\
\hline $\begin{array}{l}\text { Particulate } \\
\text { bone graft } \\
(\mathrm{n}=6)\end{array}$ & 3 & 1 & 2 & 3 & 0.34 \\
\hline $\begin{array}{l}\text { No particulate } \\
\text { bone graft } \\
(\mathrm{n}=12)\end{array}$ & 9 & 7 & 2 & 3 & \\
\hline
\end{tabular}

synostosis. ${ }^{20,21}$ Although most of the eponymous craniosynostoses are easily discerned by their clinical features, others share enough clinical similarities to warrant mutational analysis. ${ }^{18,21,22}$ A genetic diagnosis helps the surgeon to more accurately counsel the family about the child's prognosis, including the likelihood of revisionary procedures. Reported outcomes for patients undergoing FOA for "nonsyndromic" synostosis are in the range of $78 \%$ to $88 \%$ Whitaker category I or II. ${ }^{17,23}$ Similar reports of patients with FGFR3, FGFR2, and TWIST mutations have shown that, despite FOA in infancy, sagittal growth of the forehead is abnormal, and revisions are frequently required. ${ }^{5,7,12,24,25}$ Revision rates vary with diagnosis. Two comparison studies documented that all patients with Apert syndrome who have FOA in infancy will need a forehead reoperation (foreheadplasty or secondary FOA), whereas the frequencies were lower for other craniosynostotic disorders: $65 \%$, Saethre-Chotzen syndrome; $38 \%$, Pfeiffer syndrome; and $26 \%$, for Crouzon syndrome. $^{11,17}$ The second review reported that following FOA in infancy, secondary FOA or intracranial procedure was necessary in $20 \%$ of Crouzon patients, $45 \%$ of Apert patients, and $42 \%$ of Pfeiffer patients. ${ }^{24}$ Only 2 Saethre-Chotzen patients were available in this study. A recent report confirmed that $65 \%$ of patients with SaethreChotzen had a Whitaker category III or IV outcome, of whom $59 \%$ needed a secondary intracranial procedure. ${ }^{25}$
In this study of Muenke syndrome, $65 \%$ of patients required either a second FOA or foreheadplasty in childhood or adolescence. Similarly, high rates of forehead revision in this disorder have been reported by other investigators. ${ }^{5,7,12,13}$ Honnebier et al ${ }^{12}$ noted that $44 \%$ of 16 Muenke patients required a secondary intercranial procedure for recurrent supraorbital retrusion. Thomas et $\mathrm{al}^{13}$ reviewed their series of 29 patients with Muenke syndrome and found that $21 \%$ required a transcranial reoperation for elevated intracranial pressure. Their revision rate did not vary between patients with unilateral and bilateral coronal synostosis. Renier et $\mathrm{al}^{26}$ designated either a Whittaker category III or IV score in 4 (16\%) of 25 Muenke patients, in comparison to no category III or IV outcomes in patients treated with FOA for nonsyndromic brachycephaly. Cassileth et $\mathrm{al}^{5}$ (2001) reported 3 of 4 patients with Muenke syndrome required revision compared with $12 \%$ of patients with nonsyndromic craniosynostosis.

Of the variables that might have predicted an increased need for frontal revision, only age at primary FOA significantly correlated. Patients who did not require frontal revision underwent FOA in later infancy, whereas those patients who needed revision (either FOA or foreheadplasty) were younger at the time of initial FOA.
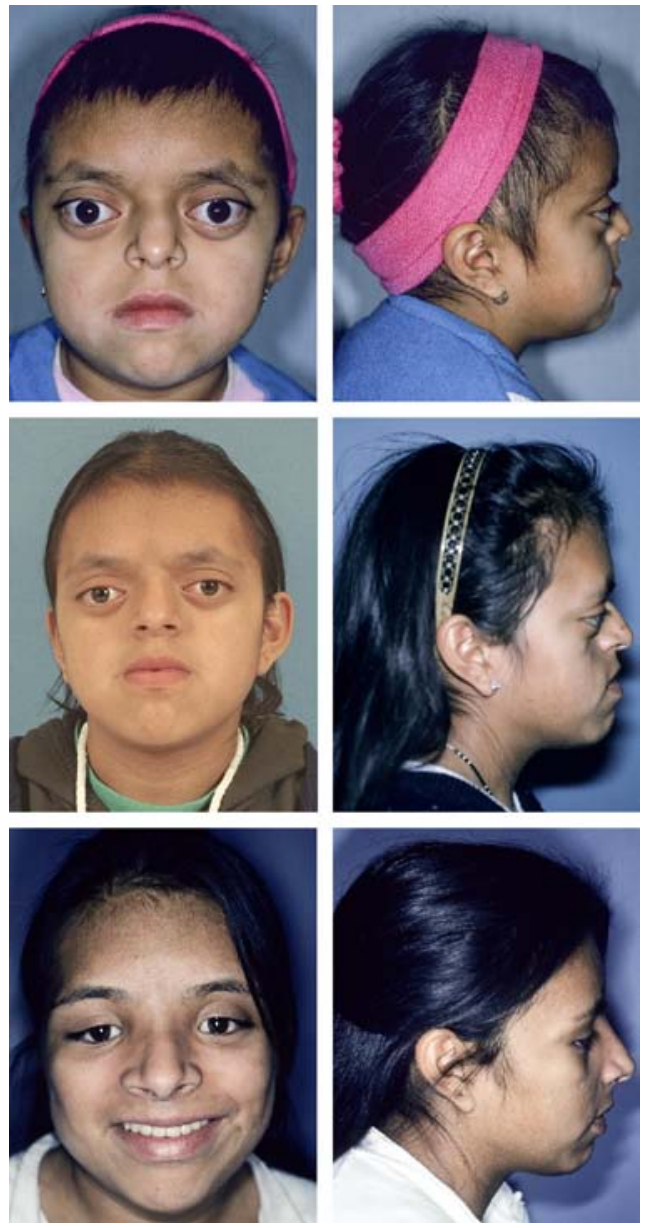

FIGURE 4. Frontal and lateral views of a patient with Muenke syndrome with coronal synostosis and midfacial hypoplasia. Before FOA at age 7 years with os-acor $-4 \mathrm{~mm}$ (above, left and right) and postoperative appearance (center, left and right). Final appearance at age 16 years (os-acor $+5 \mathrm{~mm}$ ) after Le Fort III distraction advancement and rhinoplasty (bottom, left and right). 
TABLE 4. Occlusion Data for Muenke Patients

\begin{tabular}{lc}
\hline 1st-Molar Relationship & No. Patients (\%) \\
\hline Class I & $7(41)$ \\
Class II & $6(35)$ \\
Class III & $4(24)$ \\
\hline
\end{tabular}

This finding is interesting in the context of the debate regarding the best time for frontal advancement. ${ }^{1,21}$ Some surgeons argue that early correction optimizes osseous healing of the bony gaps left by advancement and allows the rapidly growing brain to better maintain the advanced frontal bandeau. ${ }^{27}$ Other surgeons prefer to wait until closer to a year of age because most of the abnormal cranial growth and deformity have occurred, bony fixation is more stable, risk of anesthesia is lower, and tendency for relapse may be less. ${ }^{11}$ As suggested previously, the frequency of revision is likely related to the type of genetic defect. ${ }^{11}$

Several other variables appeared to positively correlate with revision rates, but their effect did not reach statistical significance. Bilateral coronal synostosis was more common than unilateral fusion and was more likely require revision, but the difference was not significant. Preoperative severity of frontal recession, as quantified by the os-acor value, was associated with a higher frontal revision rate, but this was also not significant. There was a positive correlation between length of follow-up and revision rate. Nevertheless, this observation would be expected as FGFR mutation impairs forehead growth, which normally continues into early adolescence. Vertical forehead growth should be $85 \%$ to $90 \%$ complete and frontal bone thickness $60 \%$ complete by age 6 to 8 years of age. ${ }^{11,28}$ Lastly, technical details also seemed to affect the revision rate. Revisions were less likely when the advanced orbital bandeau and frontal bones were stabilized with resorbable plates (versus wires) and buttressed with interposition bone grafts (versus none). Although the

TABLE 5. Cephalometric Data for Muenke Subjects $(n=8)$ Compared With Age- and Sex-Matched Untreated Normal Subjects $(n=8)$

\begin{tabular}{|c|c|c|c|c|}
\hline Variable & Muenke Subjects & Matched Controls & Mean Differences & Significance $(P<0.05)$ \\
\hline SNA, degrees & $80.4 \pm 6.8$ & $82.0 \pm 0.0$ & -1.6 & 1.000 \\
\hline SNB, degrees & $78.4 \pm 7.0$ & $80.9 \pm 0.0$ & -2.5 & 0.442 \\
\hline ANB, degrees & $2.0 \pm 4.8$ & $1.6 \pm 0.0$ & 0.5 & 0.442 \\
\hline P-A face height (S-Go/N-Me) (\%) & $64.6 \pm 4.6$ & $65.0 \pm 0.0$ & -0.4 & 0.442 \\
\hline Upper face height (N-ANS), mm & $45.3 \pm 3.3$ & $50.0 \pm 0.0$ & -4.7 & 0.002 \\
\hline LAFH (ANS-Me), mm & $71.7 \pm 10.9$ & $57.4 \pm 23.4$ & 14.4 & 0.195 \\
\hline UFH:LFH, upper (N-ANS/N-Gn) (\%) & $38.1 \pm 3.8$ & $45.0 \pm 0.0$ & -6.9 & 0.000 \\
\hline LFH (ANS-Me/(N-ANS+ANS-Me)) (\%) & $61.0 \pm 3.7$ & $57.0 \pm 0.0$ & 4.0 & 0.000 \\
\hline Cranio-Mx base/SN-palatal plane, degrees & $3.1 \pm 6.1$ & $7.3 \pm 0.0$ & -4.2 & 0.105 \\
\hline Palatal-mand angle (PP-MP), degrees & $34.2 \pm 6.7$ & $25.0 \pm 0.0$ & 9.2 & 0.000 \\
\hline MP-SN, degrees & $37.3 \pm 6.6$ & $33.0 \pm 0.0$ & 4.3 & 0.442 \\
\hline SN-FOP, degrees & $17.8 \pm 6.2$ & $18.6 \pm 1.1$ & -0.8 & 0.645 \\
\hline Gonial/jaw angle (Ar-Go-Me), degrees & $131.7 \pm 4.3$ & $126.0 \pm 4.2$ & 5.8 & 0.010 \\
\hline U1-SN, degrees & $105.5 \pm 8.1$ & $102.4 \pm 0.6$ & 3.1 & 0.442 \\
\hline U1-palatal plane, degrees & $108.6 \pm 7.0$ & $110.0 \pm 0.0$ & -1.4 & 0.442 \\
\hline L1-MP, degrees & $89.5 \pm 5.6$ & $95.0 \pm 0.0$ & -5.6 & 0.105 \\
\hline Interincisal angle (U1-L1), degrees & $127.8 \pm 5.4$ & $129.3 \pm 2.1$ & -1.4 & 0.721 \\
\hline U1-NPo, mm & $7.6 \pm 6.0$ & $5.3 \pm 0.7$ & 2.4 & 0.105 \\
\hline $\mathrm{U}$-incisor protrusion (U1-APo), mm & $6.3 \pm 3.9$ & $6.0 \pm 0.0$ & 0.3 & 0.721 \\
\hline $\mathrm{L} 1$ protrusion $(\mathrm{L} 1-\mathrm{APo}), \mathrm{mm}$ & $3.6 \pm 2.7$ & $2.7 \pm 0.0$ & 0.9 & 1.000 \\
\hline Overjet, $\mathrm{mm}$ & $2.7 \pm 4.8$ & $2.6 \pm 0.3$ & 0.0 & 1.000 \\
\hline Overbite, mm & $-2.5 \pm 5.4$ & $2.5 \pm 0.1$ & -5.0 & 0.000 \\
\hline Y-axis (SGn-SN), degrees & $70.1 \pm 7.1$ & $67.0 \pm 0.0$ & 3.1 & 0.105 \\
\hline Facial axis angle $\left(\mathrm{Ba}-\mathrm{Na}{ }^{\wedge} \mathrm{Pt}-\mathrm{Gn}\right)$, degrees & $-1.2 \pm 4.6$ & $-0.1 \pm 0.4$ & -1.1 & 0.645 \\
\hline $\mathrm{S}-\mathrm{N}, \mathrm{mm}$ & $66.6 \pm 3.7$ & $75.0 \pm 0.0$ & -8.4 & 0.000 \\
\hline FH-SN, degrees & $13.1 \pm 3.9$ & $6.0 \pm 0.0$ & 7.1 & 0.000 \\
\hline SN-basion, degrees & $137.6 \pm 8.9$ & $131.0 \pm 0.0$ & 6.6 & 0.105 \\
\hline Wits appraisal, mm & $0.7 \pm 5.1$ & $-1.0 \pm 0.0$ & 1.7 & 0.442 \\
\hline Mandibular body length (Go-Me), mm & $62.4 \pm 7.1$ & $75.3 \pm 6.0$ & -12.9 & 0.003 \\
\hline Mandibular length (Co-Gn), mm & $111.2 \pm 12.2$ & $111.0 \pm 7.2$ & 0.2 & 0.721 \\
\hline Midface length (Co-A), mm & $81.5 \pm 7.1$ & $87.4 \pm 3.4$ & -5.9 & 0.021 \\
\hline $\mathrm{Mx} / \mathrm{Md}$ diff (Co-Gn-Co-A), mm & $29.7 \pm 10.2$ & $19.5 \pm 3.8$ & 10.2 & 0.028 \\
\hline Nasolabial angle (Col-Sn-UL), degrees & $103.4 \pm 11.2$ & $102.0 \pm 0.0$ & 1.4 & 1.000 \\
\hline
\end{tabular}


differences were not statistically significant, we continue to use resorbable plating and cortical and particulate bone grafting in the coronal gap in all patients.

The frequency of midfacial retrusion in Muenke syndrome is unclear in the literature. In the original review by Muenke et al, ${ }^{1} 16$ of 27 patients had midfacial retrusion. The same group later reported that although midfacial hypoplasia was frequently seen in the pediatric-age-group Muenke patients, it largely resolved by adulthood. $^{7}$ A review by Reinhart et $\mathrm{al}^{29}$ documented a mean $6.8 \%$ reduction in sagittal length of the maxilla. In contrast, Honnebier et $\mathrm{al}^{12}$ found that none of 16 Muenke syndrome patients had midfacial retrusion. In our series, $24 \%$ of patients in our patients with Muenke syndrome had midfacial hypoplasia, however, and only 1 patient required Le Fort III midfacial advancement (Fig. 4).

Midfacial hypoplasia is more common in the other eponymous craniosynostosis: Apert (67\%), Pfeiffer (67\%), and Crouzon $(60 \%)$ syndromes. ${ }^{24}$ Most patients with Apert, Crouzon, and Pfeiffer need midfacial advancement; most require both Le Fort III and Le Fort I osteotomies. ${ }^{24,30}$ In Saethre-Chotzen, midfacial hypoplasia is less frequent and tends to be familial. ${ }^{25,31}$

There are several limitations to this study. First, the small sample size prohibited the possibility of finding statistical differences that might exist in our comparisons. There were several variables that appeared to correlate with revisions but failed to achieve statistical significance. It is entirely possible that, with increased study power, significance would be found. Another limitation is that all patients had not reached skeletal maturity at the time of latest follow-up. Because forehead growth is completed by age 13 years, our data on the frequency of frontal revision should not be adversely impacted by including some teenage patients in our analysis. Nevertheless, the inclusion of some skeletally immature patients could have affected our assessment of midfacial growth and position of the mandible. Thus, some patients who had a normal occlusion at the time of last follow-up could eventually exhibit an Angle class III pattern. Consequently, our findings on midfacial position should be considered preliminary; longer follow-up will provide more definitive data.

\section{ACKNOWLEDGMENT} analysis.

The authors thank Dr. Richard A. LaBrie for the statistical

\section{REFERENCES}

1. Muenke M, Gripp KW, McDonald-McGinn DM, et al. A unique point mutation in the fibroblast growth factor receptor 3 gene (FGFR3) defines a new craniosynostosis syndrome. Am J Hum Genet 1997;60:555-564

2. Reardon W, Wilkes D, Rutland P, et al. Craniosynostosis associated with FGFR3 Pro250Arg mutation in a range of clinical presentations including unisutural sporadic craniosynostosis. J Med Genet 1997;34:632-636

3. Graham JM, Braddock SR, Mortier GR, et al. Syndrome of coronal craniosynostosis with brachydactyly and carpal/tarsal coalition due to Pro250Arg mutation in FGFR3 gene. Am J Med Genet 1998;77:322-329

4. Golla A, Lichtner P, von Gernet S, et al. Phenotypic expression of the fibroblast growth factor receptor 3 ( FGFR3) mutation P250R in a large craniosynostosis family. J Med Genet 1997;34:683-684

5. Cassileth LB, Bartlett SP, Glat PM, et al. Clinical characteristics of patients with unicoronal synostosis and mutations of fibroblast growth factor receptor 3: a preliminary report. Plast Reconstr Surg 2001;108:1849-1854

6. Britto JA, Evans RD, Hayward RD, et al. From genotype to phenotype: the differential expression of $F G F, F G F R$, and $T G F-B$ genes characterizes human development and reflects clinical presentation in FGFR syndromes. Plast Reconstr Surg 2001;108:2026-2039

7. Doherty ES, Lacbawan F, Hadley DW, et al. Muenke syndrome (FGFR3-related craniosynostosis): expansion of the phenotype and review of the literature. Am J Med Genet A 2007;15:3204-3215
8. Sabatino G, DiRocco F, Zampino G, et al. Muenke syndrome. Childs Nerv Syst 2004;20:297-308

9. Keller MK, Hermann NV, Darvann TA, et al. Craniofacial morphology in Muenke syndrome. J Craniofac Surg 2007;18:374-386

10. Moloney DM, Wall SA, Ashworth GJ, et al. Prevalence of Pro250Arg mutation of fibroblast growth factor receptor 3 in coronal craniosynostosis. Lancet 1997;349:1059-1062

11. Wong GB, Kakulis EG, Mulliken JB. Analysis of fronto-orbital advancement for Apert, Crouzon, Pfeiffer, and Saethre-Chotzen syndromes. Plast Reconstr Surg 2000;105:2314-2323

12. Honnebier MB, Cabiling DS, Hetlinger M, et al. The natural history of patients treated for FGFR3-associated (Muenke-type) craniosynostosis. Plast Reconstr Surg 2008;121:919-931

13. Thomas GP, Wilkie AO, Richards PG, et al. FGFR3 P250R mutation increases the risk of reoperation in apparent 'nonsyndromic' coronal craniosynostosis. J Craniofac Surg 2005;16:347-352

14. Mulliken JB, Godwin SL, Pracharktam N, et al. The concept of the sagittal orbital-globe relationship in craniofacial surgery. Plast Reconstr Surg 1996;97:700-706

15. Kohout M, Pai L, Berenguer B, et al. New instrument for orbital anthropometry. J Craniomaxillofac Surg 1998;26:174-178

16. Pai L, Kohout M, Mulliken JB. Prospective anthropometric analysis of sagittal orbital-globe relationship following fronto-orbital advancement in childhood. Plast Reconstr Surg 1999;103:1341-1346

17. Whitaker LA, Bartlett SP, Schut L, et al. Craniosynostosis: an analysis of the timing, treatment, and complications in 164 consecutive patients. Plast Reconstr Surg 1987;80:195-212

18. Cohen MM, Maclean RB. Craniosynostosis: Diagnosis, Evolution and Management. 2nd ed. New York: Oxford University Press, 2000

19. Paznekas WA, Cunningham ML, Howard TD, et al. Genetic heterogeneity of Saethre-Chotzen syndrome, due to TWIST and FGFR mutations. Am J Hum Genet 1998;62:1370-1380

20. Arnaud E, Meneses P, Lajeunie E, et al. Postoperative mental and morphological outcome for nonsyndromic brachycephaly. Plast Reconstr Surg 2002;110:6-12

21. Mulliken JB, Gripp KW, Stolle CA, et al. Molecular analysis of patients with synostotic frontal plagiocephaly (unilateral coronal synostosis). Plast Reconstr Surg 2004;113:1899-1909

22. Robin NH. Molecular genetic advances in understanding craniosynostosis. Review. Plast Reconstr Surg 1999;103:1060-1070

23. McCarthy JG, Glasberg SB, Cutting CB, et al. Twenty-year experience with early surgery for craniosynostosis: I. Isolated craniofacial synostosis - results and unsolved problems. Plast Reconstr Surg 1995;96:272-283

24. McCarthy JG, Glasberg SB, Cutting CB, et al. Twenty-year experience with early surgery for craniosynostosis: II. The craniofacial synostosis syndromes and pansynostosis - results and unsolved problems. Plast Reconstr Surg 1995;96:284-295

25. Foo R, Guo Y, McDonald-McGinn DM, et al. The natural history of patients treated for TWIST1-confirmed Saethre-Chotzen syndrome. Plast Reconstr Surg 2009;124:2085-2095

26. Renier D, Arnaud E, Marchac D. Craniosynostosis: functional and morphologic postoperative results. Neurochirurgie 2006;52:302-310

27. Paige KT, Vega SJ, Kelly CP, et al. Age-dependent closure of bony defects after frontal orbital advancement. Plast Reconstr Surg 2006;118:977-984

28. Farkas LG. Anthropometry of the Head and Face. 2nd ed. New York: Raven Press, 1994

29. Reinhart E, Eulert S, Bill J, et al. Typical features of craniofacial growth of the FGFR3-associated coronal synostosis syndrome (so-called Muenke craniosynostosis). Mund Kiefer Gesichtschir 2003;7:132-137

30. David DJ, Sheen R. Surgical correction of Crouzon syndrome. Plast Reconstr Surg 1990;85:344-354

31. Padwa BL, Whiteman DAH, Warman M, et al. Anthropometric analysis of the phenotypic spectrum in Saethre-Chotzen syndrome in five families. In: Ortiz-Monasterio F, ed. Transactions of the 5th International Congress of Craniofacial Surgery. Bologna: Monduzzi Editore, 1994:157-158 